\title{
Estado, democracia e globalização
}

\author{
Luiz Alberto G. S. Rocha*
}

\section{Resumo}

As estruturas gerais do Estado Moderno têm se modificado fortemente diante do processo de globalização, assim também o conceito de soberania. A globalização, explicável em três vertentes: a internacionalização do capital, a integração política e a sociedade global; tem produzido diversas assimetrias nas relações internacionais e nas condições da vida humana ao redor do planeta. Para adequar o Estado às novas estruturas políticas proponho o desenvolvimento da democracia estendida como fator de legitimação da nova ordem estatal que garanta o progresso das sociedades sem perda de identidade cultural.

Palavras-chave: Soberania. Globalização. Democracia.

\section{Introdução}

$\mathrm{O}$ artigo pretende ser um resumo de idéias mais alongadas que escrevi em livro de mesmo nome publicado recentemente pela Editora Forense e que transporta àquelas páginas uma indagação visceral que tem me acompanhado por esses anos de pesquisa jurídica: como estabelecer um parâmetro aceitável do conceito de soberania dentro do contexto de crescente internacionalização das relações jurídicas?

Explica-se a pergunta foco daquele trabalho, pelo protagonismo que o conceito de soberania desempenhou, e ainda desempenha, na explicação das ciências jurídicas e políticas acerca da formação do Estado Moderno.

\footnotetext{
* O autor é Doutor em Direito do Estado pela Faculdade de Direito da Universidade de São Paulo/2003 e Professor Titular de Direito Constitucional da graduação e Mestrado em Direito da Universidade da Amazônia - Unama e da graduação da Faculdade do Pará FAP. Assessor de Desembargador, TJE/PA.
} 
Bem sei que os elementos formadores do Estado Moderno não ressoam mais contemporaneamente, diante da miríade de mudanças sociais que vivenciam os tempos atuais. São modificações trazidas, ou pelo menos alavancadas, pelo fenômeno da globalização e que resultaram em um arranjo estatal completamente diferente do que se tinha anteriormente.

Se a seara doutrinal discute o uso da expressão Estado Pós-Moderno, Segunda Modernidade ou, simplesmente, mais uma crise do Estado Moderno; a verdade inerente a todas essas concepções é que as mudanças se apresentam a olhos vistos e já a explicação da soberania como instituto absoluto e invulnerável não corresponde mais como justificativa do Estado.

$\mathrm{Na}$ tentativa de responder ao questionamento que havia me proposto naveguei entre os conceitos tradicionais de soberania desde Jean Bodin até uma visão estritamente moderna de Georges Burdeau, e, posteriormente, por paradigmas contemporâneos de Zygmunt Bauman e Milton Santos.

Para avaliar com maior precisão a revolução copernicana no conceito de soberania, utilizei a metáfora da combustão de materiais para designar o fenômeno da globalização como o catalisador dessa metamorfose conceitual. E, ao final, pincelei um novo modelo de Estado Soberano sobrevalorizando o elemento democrático, agora lançado ao cenário internacional que tomei a liberdade de chamar democracia estendida.

\section{0 marco da soberania na construção do estado moderno}

Dos diversos recursos conceituais que se possam abraçar sobre a soberania preferi optar por uma descrição mais fugaz de autores principais que consigam apresentar de forma direta e resumida o que se escreveu sobre soberania desde o século XVI até meados do XX. Isto faz com que se incorpore à pesquisa leituras de soberania de Jean Bodin, de Hans Kelsen e de Georges Burdeau.

É lógico que muitos outros poderiam se apresentar para trazer suas concepções de soberania, e o pesquisador rigoroso sempre terá um novo autor a sugerir que possa apresentar uma nuance alternativa para o movimento conceitual que se desenvolveu ao longo dos séculos. Porém, como o objetivo principal não é 
histórico-conceitual, mas histórico-prospectivo no sentido de fornecer elementos para demonstrar a mudança de perspectiva do conceito de soberania. Acredito que os referidos autores possam nos dar fundamento suficiente para tal.

No que concerne à Bodin, a referência histórica retoma a estrutura plural do poder Medieval que não encontrava um assento sistemático de organização. Posto que a estrutura de vassalagem não representava uma hierarquia rígida de poder não se encontrando uma relação interestatal estável tanto mais difícil pensar na formação de um Estado Nacional.

Neste contexto, Bodin com sua "República" apresenta o conceito moderno de soberania, pois ele mostra a urgência de sua geração em conferir ao príncipe a unidade de poder que pudesse unificar o Estado e estabilizar as relações sociais, principalmente, do ponto de vista bélico.

Sendo assim, conferir a um único soberano a unidade de poder do Estado fortalece, por reflexo, a estrutural social, pois organiza o poder social dentro de uma sistemática inquebrantável da força do Estado reunida no príncipe unificador.

Se os homens podem ser persuadidos a aceitar a vontade preeminente do órgão soberano, a oposição ficará privada de suas principais pretensões, e Henrique IV, por exemplo, pôde restaurar para a França a prosperidade que os conflitos religiosos tinham posto em perigo. ${ }^{1}$

Assim, em um Estado centralizado, unificado e laico, pode-se dotar o príncipe do poder soberano, de estar acima de qualquer outro fator de poder estatal, capaz, pelo menos dentro daquele contexto histórico, de unificar a sociedade em torno de um único projeto de Estado: o soberano.

Nesse cotejo é que surgem as características principais do conceito de soberania (e que mantiveram firmes durante muito tempo): a perpetuidade e o absolutismo. O soberano é perpétuo porque sem essa incondicionalidade temporal, o soberano deixaria de sê-lo porque se em algum momento ele pudesse perder o poder, então, de fato, a soberania do poder nunca lhe pertenceu originalmente, já que um elemento exógeno teria a capacidade de limitar sua ação no tempo.

\footnotetext{
${ }^{1}$ LASKI, Harold J. A grammar of politics. Londres: George Allen \& Unwin, 1928. p. 46.
} 
Absoluto porque não se pode conceber um poder soberano que encontre compartilhamento de poder com qualquer que seja o elemento social. O príncipe só se submete às leis divinas e naturais, não reconhece, portanto, qualquer outro como superior.

Esses conceitos a par de se mostrarem desastrosos em nosso contexto contemporâneo foram vitais para a unificação dos Estados Nacionais na figura centralizadora, mas politicamente necessária do soberano, trazendo para as ciências sociais mais um elemento de estudo: a soberania.

Dando um salto cronológico para encontrar Hans Kelsen no raiar do século $\mathrm{XX}$, e a concepção metodológica da pureza de análise científica voltada ao positivismo jurídico que se afasta do direito natural, aproximando-se da tensão entre o ser e o dever ser para compreender perfeitamente a relação possível entre a norma válida e os acontecimentos do mundo real. E que tamanha influência causou nos estudos jurídicos de todo o século XX ao redor do mundo.

Essa realidade a-ética da norma fundamental tanto defendida pelo autor austríaco é que dá o caráter dinâmico ao Direito, já que a norma jurídica já não é valorada por seu conteúdo, mas porque, e somente por isso, se valida por outra norma.

A validade desta não pode ser negada pelo fato de seu conteúdo contrariar o de uma outra norma que não pertença à ordem jurídica cuja norma fundamental é o fundamento de validade da norma em questão. A norma fundamental de uma ordem jurídica não é uma norma material. ${ }^{2}$

O que explica para Kelsen, e talvez com certa tristeza ao leitor, que sua filosofia não consegue dar existência conceitual à soberania, pois a introdução de um conceito político dentro da ordem jurídica é a coroação de teorias subjetivas jusnaturalistas do Estado, porque não explica em si, e dentro da rigidez lógica do autor, como o Estado pretende ser soberano já que a soberania elimina a possibilidade de validação superior. E encaminha a uma explicação fora do Direito, a razão de ser da soberania estatal.

É uma ilusão acreditar que normas legais podem ser derivadas do conceito como a soberania ou qualquer outro conceito legal. Normas legais são válidas so-

\footnotetext{
${ }^{2}$ KELSEN, Hans. Teoria pura do direito. 6. ed. Coimbra: Armênio Amado, 1984. p. 273.
} 
mente se elas forem criadas por legislação, costume, ou tratado; e as normas legais componentes da chamada igualdade dos Estados são válidas não porque os Estado são soberanos, mas porque essas normas são normas do direito internacional positivo.$^{3}$

Não surpreende, por conseguinte, que a questão da soberania tenha sido renegada pelo Direito por longo período, já que ela não se enquadrava na explicação lógico purista do positivismo jurídico.

Não quer dizer com isso que a soberania tenha deixado de existir enquanto elemento conceitual do Estado Moderno, mas os reflexos dessa concepção estreita da realidade estatal propiciaram uma negação reducionista da complexidade explicativa do cenário estatal, principalmente numa realidade histórica fortemente conflituosa quanto foi a geração kelseniana.

Por isso que a retomada conceitual de Georges Burdeau representa uma leitura político-democrática do conceito de soberania que ajudou a retomar as bases estatais da sociedade pós-guerras e que de certa maneira auxiliou na reconstrução do Estado Moderno em bases de social-democracia.

Isto porque Burdeau lê no poder social uma força a serviço da idéia do bem-comum e a representação ordenada da Idéia de Direito. Ou seja, a sociedade se organiza na crença (liberal?) da busca coletiva pelo bem-comum e que as regras jurídicas - as leis - sejam representações estatais do caminho a ser seguido pelos indivíduos, reunidas na Constituição do Estado.

E sendo assim, o poder precisa se legitimar no consentimento dos indivíduos que viabilizam a entrega desse poder aos governantes. Ou, por leitura inversa, a função da Idéia de Direito, em Burdeau, é fundar o princípio da legitimação sobre a qual se forma o Estado e possibilitar a continuidade do mesmo.

Isto faz-nos concluir que a única fonte viabilizadora dessa legitimação é a força do poder constituinte que concentra em um texto positivo os valores sociais e estrutura a forma de exercício legítimo de poder na sociedade.

${ }^{3}$ KELSEN, Hans. Peace through law. Chapel Hill: The University of North Carolina Press, 1944. p. 38. 
Na realidade, muito do constitucionalismo moderno se abebera na teoria carrefour de Burdeau, na explicação completa do estado moderno e liberal que se concebe a partir da legitimação constitucional do poder dos governantes. Porém, ela já não responde aos mecanismos da mundialização, para usar a expressão francesa, que se impõem no cotidiano, porque não trabalha com a necessidade de limitação recíproca de duas ou mais entidades soberanas na busca deste bem-comum.

O conceito de soberania sofreu, junto com uma série de conceitos das ciências sociais, uma metamorfose de difícil compreensão pela globalização que o conceito mais próximo de soberania não consegue abraçar.

A insuficiência da explicação clássica ou moderna do conceito de soberania do Estado mantém viva a pergunta inicial: como estabelecer um parâmetro aceitável do conceito de soberania dentro do contexto de crescente internacionalização das relações jurídicas?

\section{0 catalisador da mudança: a globalização}

De difícil explicação, mas imprescindível para a busca da resposta a pergunta acima, a globalização é fenômeno que abrange uma gama incrível de modificações na comunidade humana seja a nível interno dos Estados seja, e principalmente, nas relações internacionais fortemente desenvolvidas.

Desta feita, explicar fenômeno tão grandioso não é tarefa fácil, principalmente se pretende superar clichês superficiais de difusão de ideologias, para conceber a globalização em um contexto mais coerente com seus reflexos sociais.

Daí a tentativa de fazer tal explicação tomando como ponto de convergência principal três áreas que sofreram modificações e que dentro do contexto de soberania estatal proporcionam uma base teorética coerente com o objeto do estudo. Refiro-me ao exame da internacionalização do capital, da integração política e da sociedade global.

\subsection{A internacionalização do capital}

Na ótica de Luciano Coutinho, a globalização econômica é:

Uma etapa de forte aceleração da mudança tecnológica caracterizada pela intensa difusão das inovações telemáticas e informáticas e pela emergência de um novo padrão de 
organização da produção e da gestão na indústria e nos serviços; padrão esse caracterizado pela articulação das cadeias de suprimento e de distribuição através de redes que minimizam estoques, desperdícios, períodos de produção e tempos-de-resposta, tornando os processos mais rápidos e eficientes. ${ }^{4}$

A explicação da internacionalização do capital pode ser explicitada a partir da mudança do padrão ouro para o padrão dólar dentro do sistema econômico internacional da década de 1970.

Basicamente, o padrão ouro era o lastro da moeda soberana de um país pelo seu equivalente em ouro dando possibilidade para a livre conversão dos pagamentos internacionais por um padrão fixo do metal. Malgrado, nunca funcionou a contento tanto pelas desigualdades estruturais dos países quanto pela força que a libra esterlina detinha na hegemonia do comércio internacional.

De qualquer maneira o conflito mundial fez que, em Bretton Woods (1944), se começasse a redesenhar o cenário econômico mundial pela substituição da Inglaterra pelos EUA como avalista internacional e se criou organismos internacionais (FMI e Banco Mundial) para regular a retomada do comércio e do desenvolvimento.

Essa pode ser tomada, em síntese, como resposta capitalista ao avanço da propaganda socialista com a sua reconstrução em termos de Estado Social, de inspiração keynesiana, buscando o pleno emprego e a atenuação dos danos causados pelos mecanismos econômicos. Se seguem daí os chamados trinta anos gloriosos de contínua calmaria capitalista.

Porém, o paradoxal é que justamente os mecanismos de sucesso do capital levaram a que no começo dos anos 1970 com a desestruturação de Bretton Woods, o processo inflacionário nos EUA e a primeira crise do petróleo em 1973, o nível geral de preços subisse e a taxa de lucros estagnasse.

E aí que surge o grande drama de manter-se o financiamento das políticas públicas do Estado Social com a diminuição considerável dos lucros

${ }^{4}$ COUTINHO, Luciano. Nota sobre a natureza da globalização. Economia e Sociedade, Campinas, n. 4, p. 21, jun. 1995. 
das empresas dificultando o lastreamento contínuo do dólar como moeda internacional e provocando um desequilíbrio monetário nos EUA.

Pelo lado das relações trabalhistas, a manutenção da produção intensiva em mão-de-obra de inspiração fordista que implicava na contratação de pessoal por longo prazo e estimulava a uma indexação contínua dos salários, além de facilitar a organização sindical de trabalhadores pressionando ainda mais pela melhoria geral das condições de trabalho.

Resumindo, o cenário da economia internacional era de ineficiência da relação fordista de trabalho, estagnação da lucratividade das empresas, aceleração da inflação e aumento do déficit público.

A resposta capitalista foi de desregulamentação dos mercados que possibilitassem investimentos estrangeiros diretamente nos mercados internos, facilitação de empréstimos estrangeiros a empresas domésticas, inclusive ao mercado de seguros, e, ainda, desregulamentação para investimentos em portfólios no exterior e a conseqüente remessa de lucros. O monetarismo e o liberalismo se tornaram os principais instrumentos de política econômica.

A desregulamentação dos mercados, a bem verdade, pode ser encarada como uma nova oportunidade de investimentos diante do declínio da lucratividade das empresas pela criação de novos mercados, principalmente de mercados financeiros. Porém, a lucratividade conseguida neste novo mercado só pôde ser alcançada exatamente pela desorganização e desregulamentação do sistema financeiro internacional que possibilitou discrepâncias nas taxas de juros domésticas, de tal modo que o capital rentista pudesse garantir retorno e liquidez nas aplicações.

Essa revolução de mercado trouxe como conseqüência mais visível nas relações internacionais uma considerável dificuldade do Estado nacional de enfrentar isoladamente $\mathrm{o}$ ataque dos mercados financeiros a suas economias atrás de melhores condições de rentabilidade. Vejamos.

A regulamentação da economia doméstica pelos Bancos Centrais com instrumentos econômicos ortodoxos, passou a ter efeito bastante limitado sobre a formação da credibilidade dos investidores internacionais gerando um aumento vertiginoso nas taxas de juros nominais como forma de atrair investimentos estrangeiros. Estes mecanismos, aliado à crescente mobilidade dos capitais de curto 
prazo, força os Estados a constantes intervenções de política monetária, restringem a capacidade de controle da política fiscal e produzem importante aumento dos encargos do financiamento público. Produzindo o principal monstro da economia brasileira da longa década de 1980: a inflação de preços.

Esse arranjo sistêmico das finanças internacionais transfere o foco de importância do agente econômico devedor para o agente econômico credor internacional, pois aumenta sua capacidade especulativa ao ter o controle da liquidez dos mercados possibilitando a ele pressionar as economias nacionais por maiores desregulamentações que lhe garanta maior lucratividade e liquidez possível (remessa de lucros), inclusive com a integração dos mercados financeiros emergentes à lógica do mercado global.

O mercado sendo fundamentalmente especulativo significa dizer que sua racionalidade é de curtíssimo prazo, inadequada, portanto, à política pública de longo prazo.

Nessa lógica financeira e com a expansão dos mercados secundários, o poder econômico fica cada vez mais distante dos salários e lucros (setor produtivo) e mais próximo do capital rentista (setor financeiro).

Finalmente, em termos de soberanias nacionais, a diminuição vertiginosa da capacidade das políticas econômicas nacionais de se auto-regularem transferiu as definições de políticas monetária e fiscal a uma dependência vital de um ser amorfo chamado mercado. Assim, a internacionalização do capital não parece ter garantido condições para a realização de demandas contidas de grande parcela da humanidade materialmente débil.

\subsection{A integração política}

Do viés político institucional parece-me que a principal mudança no aspecto das relações internacionais e da soberania dos Estados tenha sido a tendência, puxada pelos países europeus, de integrar políticas públicas em áreas comuns comandadas por um organismo supranacional. Ou seja, produzir soluções conjuntas de integração política entre vizinhos geográficos que lhes garantam, conjuntamente, a manutenção da paz (como objetivo inicial) e a proteção dos mercados consumidores (como objetivo contemporâneo). 
Dessa tendência a historiografia da União Européia é o exemplo maior, partindo de um projeto de cooperação com objetivo de fortalecimento da paz da Declaração Schuman e do Tratado de Roma até a produção de soluções unas para problemas compartilhados nas diversas áreas da atividade humana, como segurança e direitos humanos, mas com enfoque principal na realização econômica das quatro liberdades: livre circulação de bens, pessoas, serviços e capitais.

A trajetória recente do projeto de uma Constituição para a Europa é emblemático nesse sentido.

Com os poucos resultados práticos do Tratado de Nice (2001), o Conselho Europeu lançou em Laeken uma convocação para os Estados-membros se reunirem na Convenção para o Futuro da Europa em que se discutiria a melhor repartição de competências da União Européia, a simplificação dos instrumentos constitutivos da União e a ampliação da democracia, transparência e eficácia.

Mas o resultado principal foi mesmo um projeto de Tratado para a primeira Constituição da União Européia, que destacava a democracia como princípio fundamental definindo o princípio da igualdade democrática, da democracia representativa e da democracia participativa. Além disso, o projeto de Tratado dá à União Européia uma personalidade política formada pelo interesse conjunto dos Estados-membros para a definição de um futuro comum e dá à União Européia uma Carta de Direitos do Homem e Liberdades Fundamentais.

Apesar da propaganda inicial sobre a revolução que uma Constituição Européia poderia trazer, na realidade havia nela uma distribuição de competências dos órgãos da União trabalhando para uma desburocratização institucional do que efetivamente avançar para um modelo diferente dos Estados Nacionais. E, mesmo com a rejeição do projeto na França e na Holanda em 2005, não se pode negar que o caminho de idas e vindas que sempre marcou a história da integração européia tem uma projeção futura de adensamento, principalmente, com a recente expansão de Estados-membros - a Europa a 25.

É o que se pode perceber com a convocação de nova Conferência Intergovernamental (CIG) com trabalhos previstos até meados de 2009.

Ainda que se reflita inicialmente e preponderantemente a partir do modelo europeu, a tendência de integração a velocidades mais cautelosas parece se repetir 
em todos os continentes. Esse modelo integrativo é mais uma variável na definição da nova soberania, ou ainda, dos mecanismos de relacionamento intra-estatal nesse cenário globalizado que compartilha, ou pelo menos aumentar a ingerência em decisões até então soberanas, no sentido clássico do termo.

\subsection{A sociedade global}

Falar em globalização como processo cultural trouxe uma série mitológica de crenças em homogeneizações culturais que reduziram sobremaneira, pelo menos a princípio, a discussão sobre como os avanços tecnológicos das comunicações e transportes, principalmente, afetaram o estilo de vida dos diversos habitantes do planeta.

A globalização tenta, de algum modo, formar um presente global sem um passado comum tornando irrelevantes tradições e histórias particulares do passado com o objetivo de unificar tendências e gostos dentro de uma ótica de eficiência cultural.

Se no início da Idade Moderna podíamos dizer que o Ocidente capitalista culturalmente correspondia à ideologia burguesa, hoje os mesmos países capitalistas são o reino da heterogeneidade estilística e discursiva sem forma. Há certa canibalização aleatória de alusões estilísticas pelas ruas das cidades, com a freqüente primazia do neo.

A globalização 'sugere que a dimensão cultural do artístico no pós-modernismo é popular (se não populista) e que ela desmantelou muitas das barreiras ao consumo cultural que pareciam implícitas no modernismo. O erro nessa impressão, é claro, está na ilusão da simetria, uma vez que em sua vigência o modernismo não era hegemônico e estava longe de ser um dominante cultural'5

Dessa forma, todas as peculiaridades culturais do pós-modernismo são sintomas e expressões de uma dialética historicamente original envolvendo a inserção dos sujeitos individuais em um conjunto multidimensional de realidades radicalmente descontínuas que vão desde os rincões de modernismo burguês até a desorganização inimaginável do capital global.

${ }^{5}$ JAMESON, Fredric. Pós-modernismo: a lógica cultural do capitalismo tardio. São Paulo: Ática, 1997. p. 321-322. 
A temática, principal, é como trabalhar com o processo cultural de maneira que a assimilação de identidades de países centrais não propague danos mundo afora empobrecendo as diversidades locais. Talvez, a melhor maneira de tratar o assunto seja pela compreensão de que a focalização no global seja apenas à nível de conceitualização no sentido de projeção do mapeamento cognitivo global, sem, volto a dizer, perder as exuberâncias de sentidos que os choques culturais nos proporcionam.

\section{Novo modelo de estado soberano}

A realidade pujante que desenha contornos nesse pós-modernismo em construção é antes de tudo uma tentativa de entendimento dessa nova configuração de mundo. É tanto verdade que o modelo clássico de soberania estatal não responde mais às condicionantes políticas atuais quanto é verdade que é preciso revigorar o elemento democrático para superar as deficiências da democracia representativa a caminho de uma Democracia Estendida.

Aqui se pretenderá delimitar o liame conectivo entre a globalização como problemática e a democracia como saída.

\subsection{A soberania é ainda um conceito necessário?}

Instigante nesse sentido é o sugestivo título do artigo de Eli Lauterpacht na International Affairs de janeiro de 1997: Soberania - mito ou realidade?6. Isto porque as modificações impostas pela globalização não permitem que vendemos os olhos para a refundação do conceito de soberania no seu sentido clássico absoluto.

De qualquer maneira, é exagero afirmar que ele não seja mais necessário nem existente, mesmo que a carga mitológica esteja presente quando Estados pretensamente soberanos, independentes são alvo de especulações financeiras internacionais ou têm seu destino marcadamente dependente de um país central. $\mathrm{O}$ que se pode constatar é que, ainda que tais fatos sejam comuns nas relações internacionais contemporâneas, são ainda os Estados Nacionais os protagonistas das

\footnotetext{
${ }^{6}$ LAUTERPACHT, Eli. Sovereignty: myth or reality? International Affairs, Cambridge, v. 73, n. 1, jan. 1997.
} 
relações internacionais. Seja qual seja o entendimento, entretanto, a verdade é que o ficcional conceito de soberania que, tão útil no passado recente, está longe de ser tão eficiente na resposta dos desafios atuais. ${ }^{7}$

Nessa fase pós-nacional, os Estados são obrigados a conviver com outros atores internos (sociedade civil organizada em nível global) e externos (organismos internacionais diversos) sob os quais não têm poder de controle. Tudo isso proporciona, no mínimo, a relativização da soberania (soberania limitada) em nome de uma organização supranacional que conjuntamente possa ensaiar soluções para seus problemas comuns.

Uma boa parte dos estudos ocidentais mantém a crença que o conceito de soberania, e mesmo do Estado Nacional, só sobreviva por meio de reforço do elemento democrático que, em uma nova roupagem, possa lhe oferecer condições para enfrentar estes novos desafios.

Isto porque a democracia confere a legitimação necessária para obrigar a sociedade ao cumprimento das leis internas dos Estados, mas muito pouco informa à soberania externa qualquer caminho a ser trabalhado. Quando muito a democracia ocidental leva à crença kantiana de que a paz perpétua poderá ser alcançada quando todos os Estados tiverem o mesmo tipo de governo.

Tanto é questionável a proposta kantiana quanto, e principalmente, é questionável se o Ocidente democrático conseguirá espalhar ao restante do mundo os condicionantes de funcionamento democrático do Estado. Mesmo porque no próprio Ocidente os mecanismos democráticos oriundos do Estado Moderno estão em permanente aperfeiçoamento diante das inerentes falibilidades que apresenta.

Algumas propostas de reformulação do Estado Nacional se apresentam como em Jürgen Habermas e seu Direito Cosmopolítico que oferece uma releitura

\footnotetext{
${ }^{7}$ A globalização fez da interdependência um princípio ativo nas relações internacionais que contradiz a própria essência da soberania, pois estabelece uma, cada vez mais complexa, rede mundial de conexões que inclui uma progressiva coleção de assuntos não econômicos que mostram conjuntamente a ineficácia de seu tratamento isolado pelo Estado nacional. "Na prática eles [os Estados] estão progressivamente embaraçando-se numa rede de interdependências e acordos regulatórios / colaborativos dos quais sair não é geralmente uma feasible option". ZACHER, Mark W. The decaying pillars of the Westphalian Temple: implications for international order and governance in governance without government: order and change in world politics. Cambrige: Cambridge University Press, 1992. p. 60.
} 
kantiana da paz mundial com a formação de uma Federação Mundial principalmente por uma reforma da Organização das Nações Unidas com a democratização do acesso ao Conselho de Segurança.

No centro desta nova ONU surgiria um Parlamento Mundial composto por representantes livremente indicados por cada país, e os povos que recusarem eleger seus representantes democraticamente serão representados por Organizações Não Governamentais (ONGs) indicadas pelo próprio Parlamento.

E ao lado deste Parlamento uma Corte Internacional com poder sancionatório supranacional.

Partilhando de uma idéia assemelhada Bertrand Badie sugere que o póssoberanismo deve explorar duas frentes principais: o neoregionalismo e os novos modos de formação da comunidade. Sobre este último ponto coloca que o processo de integração mundial deve levar, sob o princípio da responsabilização mundial, à superação das identidades de nível nacional.

A par da similitude de posicionamento, talvez o fator que os diferencie seja uma visão menos elitista de Badie ao recordar que a superação da soberania absoluta pela relativizada é uma imposição desses novos tempos, mas que a proporção dessa relativização é a peça chave da discussão, caso realmente se pretenda evitar que a mundialização se traduza em corrosão danosa da soberania em favor de um sistema de poder de apenas alguns Estados.

\subsection{Democracia e globalização}

A globalização embaralha a distinção, até então clara, entre o interno e o externo transformando-a em um conjunto de incertezas e imprecisões que reorganiza a territorialidade segundo uma lógica heterodoxa e desconforme às instituições do Estado moderno. Ela segmenta as sociedades nacionais e, ao mesmo tempo, entrelaça-as no espaço ampliado da globalidade que determina horizontes temporais fragmentados.

Nesse arranjo os institutos democráticos herdados do Estado Liberal não se mostram suficientes para absorver esses vários elementos culturais diversos.

A sociedade progressivamente se desconecta da produção normativa centrada no Estado produtor do Direito. A esfera política tem pouca capacidade de 
estabelecer funções vinculantes a outros subsistemas que obedecem a outros códigos. O deslocamento da capacidade decisória dos Estados nacionais altera profundamente todo o sistema de fontes legais, inclusive com risco de enfraquecimento da autoridade sócio-política das constituições nacionais. E diante de tanto, a democracia precisa se adaptar para somar esforços na busca de uma governança a nível global.

A democracia estendida se apresenta doravante como o locus de deliberação coletiva, onde repousarão os dilemas dos interesses sociais divergentes (democracia deliberativa), e como garantidora do direito do cidadão de observar e de agir diretamente na busca do interesse coletivo (democracia participativa).

Amplia-se o número de atores no debate social, abrem-se fronteiras para a participação coletiva do globo no entrecruzamento de informações e na interdependência de ações. Essa extensão reclamada pela pós-modernidade propõe exatamente incluir todo esse potencial discursivo no seio estatal criando lugares novos de troca, destinados exatamente à confrontação ampliada dos pontos de vista. Esse espaço de debate, novo e formalizado, substituirá com vantagens o espaço informal de negociação que não tendo regras, privilegia aqueles que podem impô-la normalmente com a agressividade que se exemplifica nos últimos episódios da pax americana.

O apogeu da democracia estendida visa justamente superar o ponto de estrangulamento da representatividade de interesses particulares da democracia moderna pela democracia representativa a partir de uma confrontação ampliada entre os diversos atores e interesses sociais em debates transversalizados de qualidade de vida, meio-ambiente, saúde, direitos humanos et cetera.

Em outras palavras, a possibilidade de governabilidade na sociedade contemporânea depende da conformação das técnicas clássicas de governo - a soberania inclusive - à nova realidade dos mecanismos democráticos. Em nível político, a capacidade de regulação governamental, erodida duplamente pelo déficit de legitimidade e pela incapacidade dos instrumentos de ação tradicionais, revela o desprestígio pela política, pelos valores republicanos, coincidindo com a sobrevalorização da esfera privada. Esse fator inviabiliza muitas vezes, como tem diagnosticado grande parte da doutrina sobre o assunto, o governo democrático ao estilo liberal. 
Daí que ao dar voz direta e formal a novos atores conjugados a nível internacional nos debates de soluções internacionais de problemas possibilita-se, à moda da pós-modernidade, a livre expressão do cidadão em que, cremos, a discussão e a consensuabilidade podem ser o produto fausto do modelo de democracia estendida, caracteristicamente pluralista e interativo, e que privilegia o processo negociado de elaboração normativa com influência de processos informais de escolhas coletivas formadas a partir de interesses heterogêneos.

No entanto, a essência de um conteúdo mínimo da democracia não se modificou e, ainda que falemos de democracia estendida é preciso observar uma estrutura valorativa mínima a ser mantida e trabalhada no pós-modernismo.

Em primeiro plano, a tolerância. É imprescindível que, em uma sociedade com diversas tendências e sentidos de realidade, a tolerância seja estimulada como alternativa plausível para a paz entre as pessoas consistente na disposição individual e coletiva a admitir modos de pensar, agir e sentir diferentes dos nossos. A tolerância deve ser entendida como dever de respeito pela dignidade e personalidade dos outros. ${ }^{8}$

Em segundo plano, as regras de convivência. O elemento democrático traz como principal vantagem a substituição do recurso à violência pelas regras de resolução democrática e pacífica dos conflitos sociais. E assim deve ser mantido dentro do relacionamento inter-estatal.

Por último, a renovação gradual da sociedade pelo livre debate de idéias. Isto é, no momento em que se permite a formação e expansão das revoluções silenciosas, feitas a partir de movimentos sociais quase imperceptíveis pela capilaridade dos pequenos debates locais que transformam tendências e costumes, o sentimento de fraternidade se espalha no meio coletivo aprofundando o sentimento republicano de compromisso ético a nível global.

\footnotetext{
${ }^{8}$ É preciso que a tolerância tome especial cuidado para que o modelo de maioria disposto na democracia não imponha a ditadura da maioria, tornando a tolerância um sistema competitivo da indeterminação dos resultados eleitorais. Isto estimularia que os indivíduos participassem na promoção de interesses individuais, projetos e valores traduzidos no resultado das urnas que acabaria muito mais por contribuir para uma lógica dispersiva que integrativa da tolerância.
} 


\section{Conclusão}

A linha evolutiva do trabalho se vinculou à demonstração inicial do conceito de soberania ao longo do pensamento jurídico, o fator de modificação do próprio Estado e, por conseqüência direta, da soberania, e, por último, uma proposta para um novo modelo de soberania que se fundaria na democracia estendida - arranjo ampliado da teoria democrática do liberalismo ocidental.

Portanto, todas as linhas estão abertas à discussão da necessidade de pensar o Estado segundo o conceito geral de que seus elementos modernos não correspondem em muito às realidades globalizadas dos dias atuais.

A democracia estendida é um compromisso de realização comum do bemsocial que não mais podendo se dar dentro de uma única comunidade estatal, pretende abarcar um compromisso humanitário global que possibilite o avanço da comunidade humana para novos patamares, afinal é de demonstração desnecessária que o processo globalizante tornou as interdependências sociais e políticas muito mais nevrálgicas do que em qualquer outro momento da história.

A democracia estendida, participativa por essência, prospecta a participação ampliada da sociedade global, construindo-se uma espécie de neocontratualismo que possa gerenciar o deslocamento, se necessário, dos elementos de soberania nacional para um órgão supranacional, diminuindo o risco de surgirem déficits de independência econômica, política e cultural.

Minha crença é que no horizonte dos diversos interesses em conflito na globalização, a democracia estendida possa manter o conjunto social unido fazendo-o crer na intertemporalidade das estruturas do Estado, por meio da fixação das regras do jogo com participação estendida dos atores sociais trazidos pelo pós-modernismo.

É a sua também?

\section{State, democracy and globalization}

\section{Abstract}

The general structures of the Modern State have been strongly changed by the globalization process, as well as the concept of sovereignty. The globalization, 
explainable in three ways: the capital internationalization, the political integration and the global society; have been produced many asymmetries in the international relations and in the human life conditions around the world. To suit the State to the new political structures, I propose the development of the extended democracy as a legitimation factor to the new state order that guaranties the progress of societies without lack of cultural identity.

Keywords: Sovereignty. Globalization. Democracy.

\section{Referências}

COUTINHO, Luciano. Nota sobre a natureza da globalização. Economia $e$ Sociedade, Campinas, n. 4, p. 21, jun. 1995.

BADIE, Bertrand. Vers la responsabilité cosmopolitique? A propos d'Habermas, après l'état-nation. Les Temps Modernes, Paris, n. 610, set./nov. 2000.

BADIE, Bertrand. Um mundo sem soberania: os estados entre o artifício e a responsabilidade. Lisboa: Piaget, 1999.

BAUMAN, Zygmunt. Modernidade e ambivalência. In: CULTURA global: nacionalismo, globalização e modernidade. Petrópolis: Vozes, 1999.

BODIN, Jean. Los seis libros de la República. Madri: Tecnos, 1997.

BURDEAU, Georges. létat. Paris: Seuil, 1970.

. Traité de science politique: l'état. Paris: LGDJ, 1949. t. 1-2.

CHANTEBOUT, Bernard. l'état selon Georges Burdeau. In : LE POUVOIR et létat dans louvre de Georges Burdeau. Paris: Economica, 1993.

HABERMAS, Jürgen. Más allá del estado nacional. Madri: Trotta, 1998.

Press, 1998.

The inclusion of the othe: studies in political theory. Cambridge: Polity

JAMESON, Fredric. Pós-modernismo: a lógica cultural do capitalismo tardio. São Paulo: Ática, 1997. 
KELSEN, Hans. Peace through law. Chapel Hill: The University of North Carolina Press, 1944.

Teoria pura do direito. 6. ed. Coimbra: Armênio Amado, 1984.

LASKI, Harold J. A grammar of politics. Londres: George Allen \& Unwin, 1928.

LAUTERPACHT, Eli. Sovereignty: myth or reality? International Affairs, Cambridge, v. 73, n. 1, jan. 1997.

SANTOS, Milton. Por uma globalização do pensamento único à consciência universal. 9. ed. Rio de Janeiro: Record, 2002.

ZACHER, Mark W. The decaying pillars of the Westphalian Temple: implications for international order and governance in governance without government: order and change in world politics. Cambrige: Cambridge University Press, 1992. 